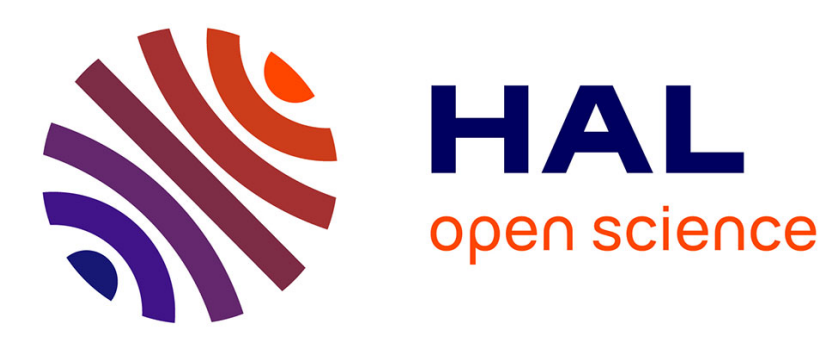

\title{
Diffusion de la lumière et effet photovoltaïque dans les céramiques ferroélectriques PLZT
}

\author{
G. Gastaud
}

\section{To cite this version:}

G. Gastaud. Diffusion de la lumière et effet photovoltaïque dans les céramiques ferroélectriques PLZT. Revue de Physique Appliquée, 1975, 10 (6), pp.424-424. 10.1051/rphysap:01975001006042400 . jpa00243940

\section{HAL Id: jpa-00243940 https://hal.science/jpa-00243940}

Submitted on 1 Jan 1975

HAL is a multi-disciplinary open access archive for the deposit and dissemination of scientific research documents, whether they are published or not. The documents may come from teaching and research institutions in France or abroad, or from public or private research centers.
L'archive ouverte pluridisciplinaire HAL, est destinée au dépôt et à la diffusion de documents scientifiques de niveau recherche, publiés ou non, émanant des établissements d'enseignement et de recherche français ou étrangers, des laboratoires publics ou privés. 


\title{
DIFFUSION DE LA LUMIĚRE ET EFFET PHOTOVOLTAÏQUE DANS LES CÉRAMIQUES FERROÉLECTRIQUES PLZT
}

\author{
G. GASTAUD
}

Thomson-CSF, Laboratoire Central de Recherches, BP 10, 91401 Orsay, France

\begin{abstract}
Résumé. - Les céramiques PLZT de composition $\mathrm{Fb}_{0,93} \mathrm{La}_{0,07} \mathrm{Zr}_{0,65} \mathrm{Ti}_{0,35} \mathrm{O}_{3}$ frittées sous pression sont transparentes bien que leur température de Curie soit supérieure à la température ambiante $\left(T_{\mathrm{c}} \simeq 180^{\circ} \mathrm{C}\right)$. Toutefois, elles diffusent la lumière dans un angle $\theta$ d'autant plus faible que les axes optiques des différents grains sont mieux alignés, c'est-à-dire que la polarisation spontanée macroscopique $\left\langle\boldsymbol{P}_{\mathrm{s}}\right\rangle$ est plus grande. Nous décrirons une mesure précise de la dépendance $\left.\theta\left(<\boldsymbol{P}_{\mathrm{s}}\right\rangle\right)$, où la polarisation est mesurée d'une façon non destructive par effet photovoltaïque : nous montrons tout d'abord que le photocourant est fonction linéaire de $\left\langle P_{\mathrm{s}}\right\rangle$, les différentes valeurs de $\left\langle P_{\mathrm{s}}\right\rangle$ étant obtenues par dépolarisation électrique ou dépolarisation thermique.

Le photocourant étant alors pris comme mesure du taux d'alignement de la polarisation des différents grains, nous en déduisons un modèle qui rend compte des différents états de diffusion observés dans les céramiques ferroélectriques transparentes PLZT.
\end{abstract}

